\title{
EFFECTS OF TIBA AND RHIZOBIUM APPLICATION ON GROWTH, YIELD AND BIOCHEMICAL COMPONENTS OF BRRI DHAN-55 (ORYZA SATIVA L.)
}

\author{
Nasrin Akhter Doel, AMM Golam Adam*, Farhana Islam Khan, \\ and Hasna Hena Begum
}

Department of Botany, Jagannath University, Dhaka-1100, Bangladesh

Keywords: Oryza sativa L., TIBA, Rhizobium, Growth, Yield, Biochemical components

\begin{abstract}
Effects of TIBA $(10,25,50 \mathrm{ppm})$ and Rhizobium inoculation on growth, yield and biochemical components of BRRI Dhan-55 were investigated. Results showed that application of $10 \mathrm{ppm}$ TIBA produced tallest plant, higher number of tillers and leaves per plant although statistically identical to control. The Rhizobium and TIBA treatments had mostly retarding effects on dry weight of leaves, shoots and roots where the lowest values was obtained from Rhizobium application. Leaf area ratio was positively affected by TIBA and Rhizobium treatments except due to $10 \mathrm{ppm}$ where, significantly maximum value was noted from Rhizobium treatment. Specific leaf weight, relative growth rate and net assimilation rate were negatively responded following all treatments and the least value was also recorded from Rhizobium treatment in each cases. Yield attributes and yield of BRRI Dhan-55 were both positively and negatively influenced by Rhizobium and TIBA treatments. The highest harvest index was found in Rhizobium treated plants. The only increase in yield per plant due to 10 ppm TIBA was $2.48 \%$ over the control but statistically similar to control. Results showed that Rhizobium inoculation had showed lowest value in protein content of leaves and seeds. Application of TIBA treatments had significant positive effects on protein content of leaves at flowering stage. However, the influence was rather negative at both tillering and grain filling stages. The 25 ppm TIBA resulted significantly maximum protein content of seeds followed by $10 \mathrm{ppm}$.
\end{abstract}

\section{Introduction}

Rice (Oryza sativa L.) covers about $77 \%$ of agricultural land and engages about $70 \%$ of total population of Bangladesh and the contribution of rice to GDP is about $18 \%$ (Chowdhury and Hassan 2013). It is the single most important crop which is a primary source for half of the world's population. Phytohormones are the magic chemicals that could increase agricultural production at an unprecedented rate and help in removing and circumventing many of the barriers imposed by genetics and environment. Investigations throughout the world revealed that the application of TIBA (2,3,5 tri-iodobenzoic acid) at optimum concentration had stimulatory effects on growth, yield and biochemical components of different plants (Adam and Jahan 2014, Jahan and Khan 2014, Munira 2015, Islam and Jahan 2019). But, reports regarding the effect of TIBA on rice crops are limited from both home and abroad (Adam et al. 2015, Adam et al.2018).

On the other hand, Dobbelaere et al. (2003), Alikhani et al. (2006) reported various mechanisms in plant growth promoting activities of Rhizobium sp. Findings of different investigation revealed that plant growth promoting bacteria have potential enhancement effect on growth and yield of some rice varieties (Hussain et al. 2009, Tan et al. 2015). The Rhizobium sp. can also help in increasing the production of non-legume plants by promoting growth and enduring the abiotic and biotic stress (Oladele and Awodun 2014).

*Author for correspondence: <adamammg@bot.jnu.ac.bd>. 
In Bangladesh, very few experiments have been done with rice using Rhizobium inoculation (Biswas et al. 2000, Hussain et al. 2009). Therefore, an attempt was taken to evaluate the responses of TIBA and Rhizobium inoculation on the growth, yield and biochemical components of rice, var. BRRI Dhan-55.

\section{Materials and Methods}

A pot experiment was conducted at the botanical garden of the Department of Botany, Jagannath University, Dhaka. A high yielding transplanting popular Aush variety, BRRI Dhan-55 which was released in 2011 was used in this investigation. The experiment was laid out in RCBD with five replications for each treatment. Seeds of BRRI Dhan-55 were collected from Bangladesh Rice Research Institute (BRRI), Gazipur whereas, Rhizobium strain (Rhizobium BARI Rca 259) was collected. The experiment consisted of five treatments viz. control (without Rhizobium sp. and TIBA, seed inoculated with Rhizobium sp., foliar application of 10, 25 and 50 ppm TIBA. Seeds were surface sterilized with Captan 200 before sowing to avoid fungal infection and were kept in darkness for $48 \mathrm{hrs}$ for germination. In case of Rhizobium inoculation each seed was inoculated directly with $1 \mathrm{ml}$ of bacterial culture $\left(10^{8} \mathrm{CFU} / \mathrm{ml}\right)$ grown in nutrient broth (Aarab et al. 2015). After inoculation the inoculated seeds were kept for $2 \mathrm{hrs}$ (Hussain et al. 2009). Seeds were sown in the seed bed and seedlings were transplanted to experimental pots $(25 \times 30 \mathrm{~cm})$ at 4-leaf stage at the age 25 days after sowing. Each pot was filled with $9.0 \mathrm{~kg}$ air dried soil. Three hills were placed in each pot, each hill containing one seedling. Cultural practices viz. thinning, irrigation and weeding and fertilizer application were done following Hand Book of Agricultural Technology (Chowdhury and Hassan 2013) and Fertilizer Recommendation Guide (2012) respectively. Cow dung was also mixed with soil uniformly during pot preparation. Foliar application of TIBA was done in sunny early morning at 30 days after transplanting. Growth parameters viz. plant height, number of tillers and leaves per plant, dry weight of leaves, shoot and root per plant, leaf area ratio, specific leaf weight, relative growth rate and net assimilation rate and all yield parameters were recorded at harvest. Whereas, Leaf area ratio, specific leaf weight, relative growth rate and net assimilation were calculated using classical growth analysis methods (Radford 1967, Gardner et al. 1985). Pigment and protein contents of fresh leaves were determined at three different stages $v i z$. tillering, flowering and grain filling stages following standard procedures (Mckinney 1940, Lowry et al. 1951, von Wettstein 1957, Maclachalan and Zalik 1963). Protein content of fresh seeds was also determined after harvest. Plants were harvested at the age of 135 days. Ten plants from each treatment were harvested separately to record data on different parameters. Data were analyzed statistically (Steel et al. 1997) and treatment means were compared by LSD test at 5\% level of significance.

\section{Results and Discussion}

Results presented in Table 1 showed that application of different TIBA treatments had both stimulatory and retarding effect on plant height, number of tillers and leaves per plant in most of the cases. Here, application of $10 \mathrm{ppm}$ TIBA although produced tallest plant and maximum number of leaves per plant but statistically at par with control. The present results are fairly in agreement with the findings of Islam (2014) on BRRI Dhan-44 and Munira (2015) on BARI Maize-6. In addition, application of TIBA treatments had retarding effects on plant height of chickpea (Islam and Jahan 2019) and stimulatory effect on number of branches and leaves per plant in mungbean (Adam and Jahan 2014) and chickpea (Islam and Jahan 2019). Seed treated with Rhizobium resulted significantly shortest plant, lowest number of tillers and leaves per plant. In chickpea, Jahan et al. (2018) also recorded the lowest number of primary branches per plant due to Rhizobium treatment although in case of height it was increased non-significantly. However, 
results of Hoque and Haq (1994) on lentil and Togay et al. (2008) on chickpea reported that seed inoculated with Rhizobium significantly increased plant height.

Findings of this investigation indicated that dry weight of leaves and shoot decreased following TIBA and Rhizobium treatments but was significant due to Rhizobium inoculation. Increase in dry weight of root was obtained from 10 and $50 \mathrm{ppm}$ TIBA treatments where, the maximum was due to $10 \mathrm{ppm}$ TIBA application although statistically identical to control. Application of TIBA treatments had both increasing and decreasing effect on total dry matter per plant in BARI Mung-5 (Adam and Jahan 2014) and BARI Chola-7 (Islam and Jahan 2019). Seeds treated with Rhizobium also produced significantly lowest dry weight of root. This results are in agreement with the findings of Jahan et al. (2018) where they obtained lowest dry weight of shoot and root of chickpea from Rhizobium treatment. However, results of Ogutcu et al. (2010) had revealed that bacterial inoculations significantly increased dry weight of root in chickpea.

Leaf area ratio of BRRI Dhan-55 were recorded significantly higher due to all treatments and the maximum was noted from Rhizobium treated plants. Application of TIBA treatments produced higher LAR at 10 days after spray and then decreased gradually in BRRI Dhan-44 (Adam et al. 2015). Specific leaf weight of BRRI Dhan-55 was found to reduced following all treatments and was significant due to Rhizobium inoculation. Findings indicated that different concentrations of TIBA and Rhizobium inoculation had not produced any better results in relative growth rate (RGR) and net assimilation rate (NAR) of BRRI Dhan-55 and the minimum was observed from Rhizobium treated plants. Adam et al. (2015) recorded both stimulating and retarding effects of TIBA on SLW, RGR and NAR of BRRI Dhan-44 at different days after spray. The probable reason of decreasing RGR could be attributed to shading of lower leaves by upper leaves (Thorne 1961).

Application of TIBA and Rhizobium inoculum showed mostly retarding effects on yield attributes and yield of BRRI dhan-55 but with non-significant variations (Table 2). The maximum number of effective tillers per plant (15.10) was recorded from 10 ppm TIBA treatments although statistically at par to control and $50 \mathrm{ppm}$ treatments. The only increase in number of non-effective tillers per plant was obtained from $50 \mathrm{ppm}$ TIBA treatment but not significantly different from control and $10 \mathrm{ppm}$ TIBA treatments. However, Rhizobium treated plants produced significantly lowest value in both the number of effective and non-effective tillers per plant. Results of this experiment is more or less similar to the findings of Adam et al. (2018) where, TIBA treatments had non-significant response on the number of effective and non-effective tillers per plant in BRRI Dhan-44. Outcome of Biswas et al. (2000) have showed increased number of panicles per plant of rice due to inoculation of rice seeds with Rhizobium sp. which is not in consistence with the findings of the present work.

Results revealed that length and dry weight of panicles per plant reduced following all treatments except $10 \mathrm{ppm}$ TIBA and decrease was significant due to Rhizobium treatment only. Number of grains per plant was negatively influenced due to all treatments where all the treatments produced statistically identical value to control. Increase in \% of filled grains per panicle was noted from $50 \mathrm{ppm}$ TIBA only and was significantly higher than all other treatments. Results obtained in case of length of panicles, dry weight of panicles, number of grains per panicle and \% of filled grain per panicle are in contrary with the findings of Adam et al. (2018) in BRRI Dhan-44. Findings in case of number of grains per plant are moderately in agreement with the outcome of Islam and Jahan (2019) in BARI Chola-7.

The highest per cent $38.47 \%$ of un-filled grains per panicle was found in Rhizobium treated plants followed by 10 and $25 \mathrm{ppm}$ TIBA treatments respectively. However, plants of $50 \mathrm{ppm}$ TIBA had 


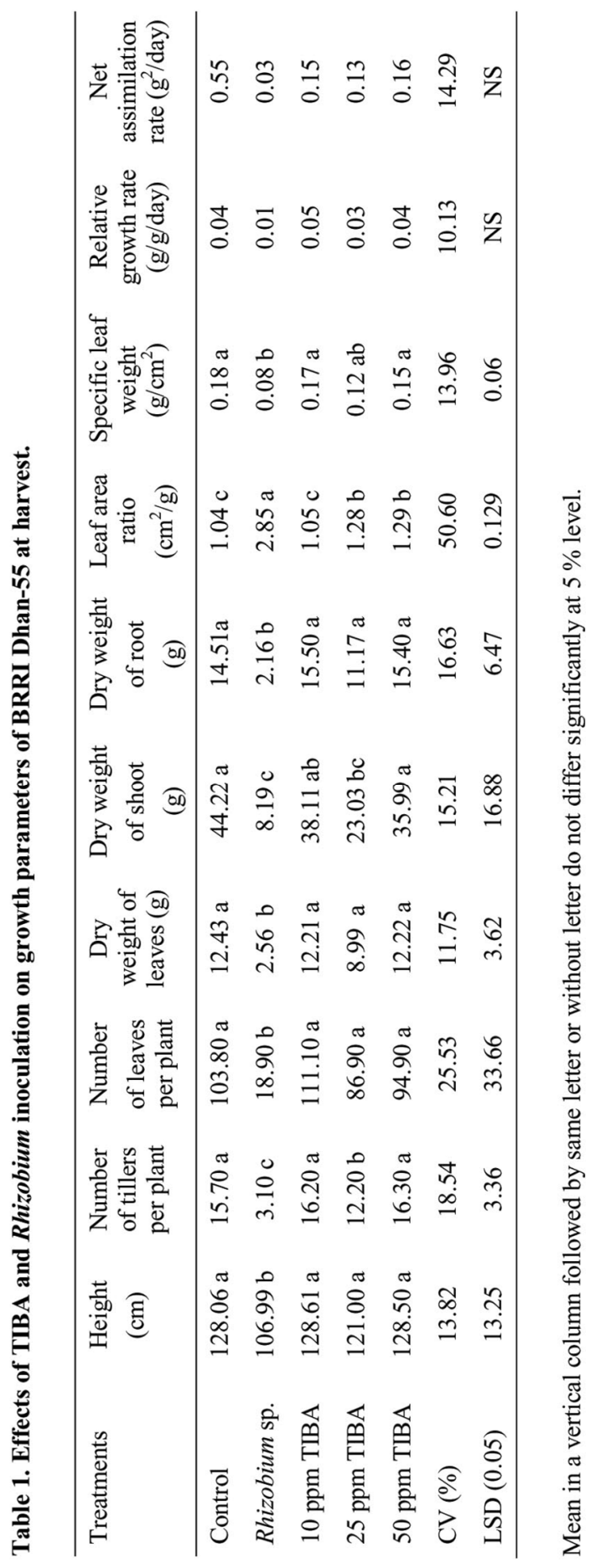




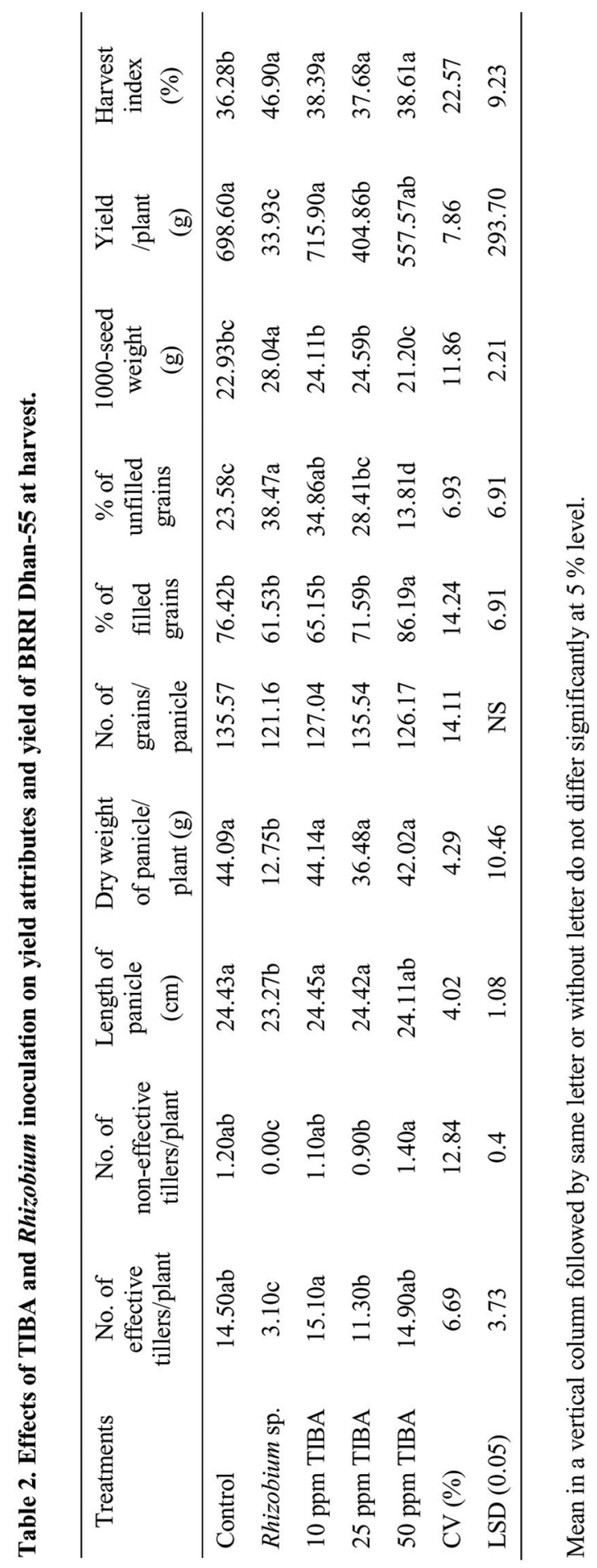




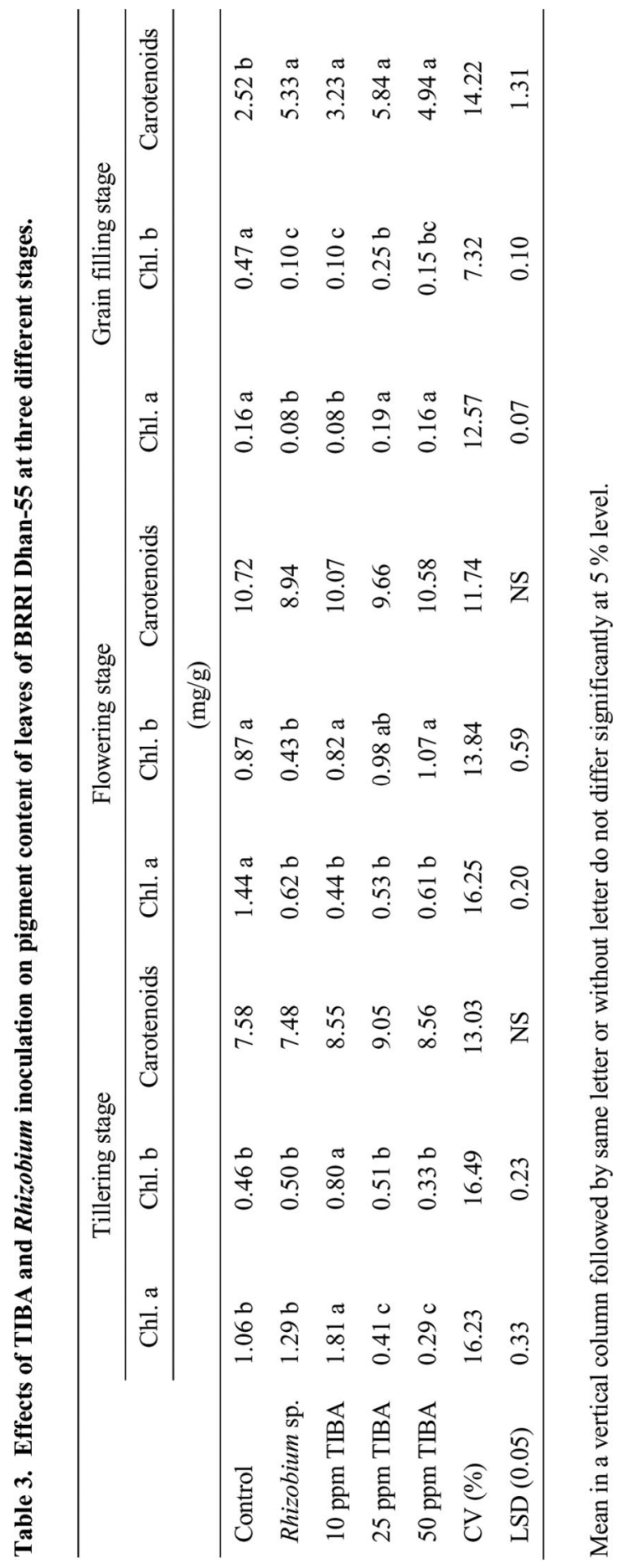


produced significantly lowest $\%$ of un-filled grains per panicle. Application of TIBA treatments had both inducing and retarding responses on $\%$ of un-filled grains per panicle but with nonsignificant variations (Adam et al. 2018). Oladele and Awodun (2014) reported that inoculation of seeds by Rhizobium sp. produced longest panicle, maximum number of grains and un-filled grains per panicle in rice plants which is partially in agreement to the findings of present investigation.

Findings presented in Table 2 indicated that Rhizobium treated plants resulted significantly maximum 1000-seed weight whereas, application of 10 and $25 \mathrm{ppm}$ although produced significantly higher 1000 -seed weight than $50 \mathrm{ppm}$ TIBA but statistically similar to control. Outcome of Hussain et al. (2009) revealed that Rhizobium sp. had produced significantly higher 1000-grain weight of rice than control treatment. By applying TIBA, similar results of increase in 100-seed weight of BARI Chola-7 was noted by Islam and Jahan (2019). Yield per plant of BRRI Dhan-55 was slightly increased following $10 \mathrm{ppm}$ TIBA treatment although statistically identical to control and $50 \mathrm{ppm}$ TIBA applications. Increase in yield per plant of BRRI Dhan-55 due to 10 ppm TIBA was $2.48 \%$ over the control. Results also showed that Rhizobium treated plants produced significantly lowest amount of yield. Foliar application of TIBA had resulted significantly higher yield per plant in BRRI Dhan-44 (Adam et al. 2018). However, Islam and Jahan (2019) recorded significantly higher yield per plant due to 10 and 20 ppm TIBA treatment but concentrations above $20 \mathrm{ppm}$ decreased yield non-significantly.

Significantly higher harvest index were recorded following all treatments where the maximum was obtained from Rhizobium treated plants followed by 50,10 and 25 ppm TIBA respectively. Previous investigations revealed that TIBA treatments resulted higher harvest index in various crops but with similar statistical values (Adam et al. 2018, Islam and Jahan 2019). The most probable reason for obtaining maximum harvest index in Rhizobium treated plants might be due to the production of higher 1000-seed weight which ultimately increased economic yield.

Pigment contents of leaves decreased with few exceptions due to application of TIBA and Rhizobium inoculum (Table 3). Significantly higher chl. a and chl. b was noted from 25 ppm TIBA at tillering stage whereas, at grain filling stage, all treatments produced significantly higher carotenoids content than control. Results also revealed that the effect of magnitude of TIBA were different depending on the concentration and stage of plant growth. Findings on pigment content of leaves are in accord with the results of Munira (2015) in maize and Adam et al. (2018) in rice where, they have observed that pigment content of TIBA treated plants may increase or decrease depending on the concentrations used and also on the plant.

Table 4. Effects of TIBA and Rhizobium inoculation on protein content of leaves and seeds of BRRI Dhan-55 at different stages.

\begin{tabular}{lcccc}
\hline Treatments & \multicolumn{3}{c}{ Protein content of leaves(mg/g) } & $\begin{array}{c}\text { Protein content of seeds } \\
(\mathrm{mg} / \mathrm{g})\end{array}$ \\
\cline { 2 - 5 } & Tillering stage & Flowering stage & Grain filling stage & At harvest \\
\hline Control & $465.63 \mathrm{a}$ & $18.88 \mathrm{~b}$ & $28.56 \mathrm{a}$ & $10.18 \mathrm{c}$ \\
Rhizobium sp. & $225.00 \mathrm{c}$ & $12.94 \mathrm{c}$ & $15.65 \mathrm{c}$ & $5.05 \mathrm{~d}$ \\
10 ppm TIBA & $311.00 \mathrm{bc}$ & $27.63 \mathrm{a}$ & $24.04 \mathrm{ab}$ & $13.00 \mathrm{~b}$ \\
25 ppm TIBA & $315.88 \mathrm{~b}$ & $25.88 \mathrm{a}$ & $22.83 \mathrm{abc}$ & $18.25 \mathrm{a}$ \\
50 ppm TIBA & $379.75 \mathrm{ab}$ & $21.40 \mathrm{~b}$ & $17.08 \mathrm{~b}$ & $5.11 \mathrm{~d}$ \\
CV $(\%)$ & 25.78 & 26.34 & 26.72 & 8.11 \\
LSD $(0.05)$ & 86.22 & 4.26 & 7.51 & 1.84 \\
\hline
\end{tabular}

Mean in a vertical column followed by same letter or without letter do not differ significantly at $5 \%$ level. 
Results presented in Table 4 showed that TIBA treatments had significant positive effects on protein content of leaves at flowering stage. However, the influence was rather negative at both tillering and grain filling stages. Foliar application of TIBA had affirmative response on protein content of leaves at tillering stage and negative effects at flowering and grain filling stages (Adam et al. 2018). Results also showed that at harvest, significantly highest protein content of seeds $(18.25 \mathrm{mg} / \mathrm{g})$ was obtained from $25 \mathrm{ppm}$ followed by $10 \mathrm{ppm}$ TIBA treatment $(13.00 \mathrm{mg} / \mathrm{g})$. The least protein content of seeds $(5.05 \mathrm{mg} / \mathrm{g})$ was observed from Rhizobium treated plants which was statistically identical to $50 \mathrm{ppm}$ TIBA but significantly lower than rest of the treatments. The present findings are also in agreement with the findings of Munira (2015).

\section{References}

Aarab S, Ollero FJ, Megias M, Laglaovi A, Bakkali M and Arakrak A 2015. Isolation and screening of inorganic phosphate solubilizing Pseudomonas strains from rice rhizosphere soil from North Western Morocco. American J. Res. Commun. 3(4): 29-39.

Adam AMMG and Jahan N 2014. Growth and yield of BARI Mung-5 (Vigna radiata L. Wilczek) following TIBA application. Dhaka Univ. J. Biol. Sci. 23(2): 179-185.

Adam AMMG, Islam R and Begum HH 2018. Yield and biochemical attributes of BRRI dhan-44 (Oryza sativa L.) as affected byTIBA application. J. Asiat. Soc. Bangladesh Sci. 44(2): 117-125.

Adam AMMG, Islam R, Begum HH and Naher MK 2015. Growth analysis of BRRI dhan-44 (Oryza sativa L.) following 2,3,5-Triiodobenzoic (TIBA) acid application. J. Asiat. Soc. Bangladesh Sci. 41(1): 67-74.

Alikhani HA, Saleh-Rastin N and Antoun H 2006. Phosphate solubilization activity of rhizobia native to Iranian soils. Plant Soil. 287: 35-41.

Biswas JC, Ladha JK, Dazzo FB, Yanni YG and Rolfe BG 2000. Rhizobia inoculation influences seedling vigor and yield of rice. Agronomy J. 92: 880-886.

Chowdhury MAH and Hassan MS 2013. Hand Book of Agricultural Technology. Bangladesh Agricultural Technology. Bangladesh Agricultural Research Council, Farmgate, Dhaka. 230pp.

Dobbelaere S, Vanderleyden J and Okon Y 2003. Plant growth promoting effects of diazotrophs in the rhizosphere. Plant Soil. 22: 107-149.

Fertilizer Recommendation Guide 2012. Bangladesh Agricultural Research Council, Farmgate, Dhaka-1215. 274pp.

Gardner FP, Pearce RB and Mitchell RL 1985. Physiology of crop plants. Iowa State University press Ames. p.164-186.

Hoque MM and Haq MF 1994. Rhizobial inoculation and fertilization of lentil in Bangladesh. Lens Newsletter. 21: 29-30.

Hussain MB, Mehboob I, Zahir ZA, Naveed M and Azhar HN 2009. Potential of Rhizobium spp. for improving growth \& yield of rice (Oryza sativa L.). Soil Environ. 28: 49-55.

Islam and Jahan 2019. Growth and yield responses of chickpea var. BARI Chola-7 following application of TIBA. Bangladesh J. Bot. 48(3): 603-608.

Islam R 2014. Physiological, biochemical and yield responses of BRRI dhan-44 (Oryza sativa L.) following 2,3,5-Triiodo benzoic acid (TIBA) application. M.Sc. Thesis, Department of Botany, Jagannath University, Dhaka. 108pp.

Jahan N and Khan S 2014. Effect of TIBA on growth, yield and yield component of soybean. J. Asiat. Soc. Bangladesh Sci. 40(1): 89-96.

Jahan T, Khan FI and Adam AMMG 2018. Growth, yield and biochemical responses of BARI Chhola-9 (Cicer arietinum L.) to $\mathrm{GA}_{3}$ and Rhizobium application. Bangladesh J. Bot. 47(4): 839-846.

Lowry OH, Rosebrough NJ, Farr AL and Randall RJ 1951. Protein measurement with folin phenol reagent. J. Boil. Chem. 193: 265-275.

Maclachalan S and Zalik S 1963. Plastid structure, chlorophyll concentration and free amino acid composition of a chlorophyll mutant of barley. Can. J. Bot. 41: 1053-1062. 
Mckinney G 1940. Criteria for purity of chlorophyll preparations. J. Biol. Chem. 132: 91-107.

Munira S 2015. Growth, yield and biochemical responses of BARI Maize-6 (Zea mays L.) as affected by TIBA application. M.Sc. Thesis, Department of Botany, Jagannath University, Dhaka. 110pp.

Ogutcu H, Kasimoglu C and Elkocae E 2010. Effects of rhizobium strains isolated from wild chickpeas on the growth and symbiotic performance of chickpeas (Cicer arietinum L.) under salt stress. Turkey J. Agric. 34: 361-371.

Oladele S and Awodun M 2014. Response of lowland rice to biofertilizers inoculation and their effects on growth and yield in South Western Nigeria. J. Agri. Environ. Sci. 3 (2): 371-390.

Radford, PJ 1967. Growth analysis formulae: their use and abuse. Crop Sci. 7: 171-175.

Steel RGD, Torrie JH and Dickey DA 1997. Principles and procedures of statistics. McGraw Hill Book Co. Inc. New York. 666pp.

Tan KZ, Radziah O, Halimi MS, Khairuddin AR and Shamsuddin ZH 2015. Assessment of plant growth promoting rhizobacteria (PGPR) and rhizobia as multi strain biofertilizer on growth \& $\mathrm{N}_{2}$ fixation of rice plant. Australian J. Crop Sci. 9(12): 1257-1264.

Thorne GN 1961. Effects of age and environment on net assimilation rate of barley. Ann. Bot. 25: 29-38.

Togay N, Togay Y, Cimrin KM, Turan M 2008. Effect of Rhizobium inoculation, sulfur and phosphorus application on yield, yield components and nutrient uptake in chick pea (Cicer aretinum L.). African J. Biotechn. 7(6): 776-782.

von-Wettstein D 1957.Chlorophyll-lethal under Submikroskopisoche Formechse der Plastiden. Expt. Cell Res. 12: 427-507.

(Manuscript received on 19 May, 2021; revised on 7 December, 2021) 